\title{
STRATEGI MENULIS DPLT \\ (DENGARKAN, PIKIRKAN, LENGKAPI, DAN TULISKAN) \\ DALAM MENGEMBANGKAN KARAKTER RELIGIUS
}

\author{
Muhammad Majdi ${ }^{1}$, Lailatul Husna ${ }^{2}$, Noor Hidayah ${ }^{3}$ \\ Dosen $^{1}$ dan Mahasiswa ${ }^{2.3}$, Sekolah Tinggi Ilmu Al-Quran (STIQ) Amuntai, \\ Kalimantan Selatan \\ Email: Muhammadmajdi755@gmail.com
}

\begin{abstract}
Abstrak
Karakter Religius menjadi salah satu pondasi yang penting bagi peserta didik dalam bekalnya menjadi makhluk sosial. Hal tersebut melatar belakangi penelitian ini yang dikolaborasikan dengan pembelajaran menulis kalimat pada jenjang sekolah dasar dengan maksud menumbuhkan jiwa religiusnya dengan beberapa indikator seperti sikap patuh menjalankan ibadah yang dianut, saling menghargai, tidak membeda-bedakan teman yang beragama lain, hidup rukun dengan semua teman, dan memberi salam kepada semua orang ketika sedang bertemu. Metode penelitian kualitatif deskriptif dengan pendekatan induktif. Hasil penelitian implementasi strategi DPLT (dengarkan, pikirkan, lengkapi dan tuliskan) berjalan dengan baik sesuai langkah-langkahnya yang terdiri dari bagian 1) dengarkan, 2) pikirkan, 3)lengkapi dan 4) tuliskan. Sedangkan korelasi pendidikan karakter religius dengan strategi DPLT terdapat pada beberapa langkah penerapan strategi pembelajaran sesuai dengan indikator pendidikan karakter religius, seperti dalam adab berpakaian, memberi dan menjeawab salam, berdoa sebelum melakukan kegiatan, interaksi dengan gerakan-gerakan yang disunahkan oleh agama, menghargai serta sopan antara siswa dengan siswa dan siswa dengan guru.
\end{abstract}

Kata kunci: Pembelajaran Menulis, Strategi DPLT, Karakter Religius

\section{PENDAHULUAN}

Pendidikan Karakter adalah pendidikan akhlak yang diimplementasikan dalam kehidupan. Menurut Zubaedi pendidikan karakter adalah pendidikan budi pekerti plus, pada hakikatnya adalah program pengajaran yang ditujukan dalam mengembangkan watak dan tabiat peserta didik. $^{1}$

Penelitian ini mengambil pendidikan karakter religius menjadi inti pembahasan. Menurut Daryanto dan Suryanti karakter religius adalah sikap dan perilaku yang patuh dalam melaksanakan ajaran agama yang dianutnya, toleran terhadap pelaksanaan ibadah agama lain serta

${ }^{1}$ Zubaedi, Desain Pendidikan Karakter: Konsepsi dan Aplikasinya dalam Lembaga Pendidikan (Jakarta: Kencana, 2011), h. 25.

Al-Madrasah: Jurnal Ilmiah Pendidikan Madrasah Ibtidaiyah Vol. 6, No. 2, April-Juni 2022 
Muhammad Majdi, Lailatul Husna, Noor Hidayah : Strategi Menulis DPLT (Dengarkan, Pikirkan, Lengkapi, dan Tuliskan) Dalam Mengembangkan Karakter Religius

hidup rukun dengan pemeluk agama lainnya. ${ }^{2}$ Kemudian dari pengertian tersebut dikembangkan menjadi beberapa indikator, menurut Annis Titi Utami, aspek sikap dan perilaku yang patuh dalam melaksanakan ajaran agama yang dianutnya dapat dijabarkan kembali menjadi indikatorindikator seperti melakukan sholat, berpuasa, membayar zakat. Aspek toleran terhadap pelaksanaan ibadah agama lain dapat dijabarkan menjadi beberapa indikator seperti memberi kesempatan siswa untuk melakukan ibadah, saling menghargai teman yang sedang melakukan ibadah. Aspek hidup rukun dengan pemeluk agama lain dapat dijabarkan menjadi indikator seperti tidak membeda-bedakan teman yang beragama lain, hidup rukun dengan semua teman, memberi salam kepada semua orang ketika sedang bertemu. ${ }^{3}$

Materi bahasa Indonesia yang di ajarkan adalah tentang Pola Dasar Kalimat (SPOK). Menurut Alwi, dkk., kalimat adalah satuan bahasa terkecil, dalam wujud lisan atau tulisan yang mengungkapkan pikiran yang utuh. Dalam wujud lisan, kalimat diucapkan dengan suara naik turun dan keras lembut, disela jeda, dan diakhiri dengan intonasi akhir yang diikuti oleh kesenyapan yang mencegah terjadinya perpaduan ataupun asimilasi bunyi ataupun proses fonologis lainnya. Dalam wujud tulisan berhuruf Latin, kalimat dimulai dengan huruf kapital dan diakhiri dengan tanda titik (.), tanda tanya (?), tanda seru (!); sementara itu, di dalamnya disertakan pula berbagai tanda baca seperti $\operatorname{koma}($,$) , titik dua (:), tanda pisah (-), dan spasi. { }^{4}$ Menurut Rahardi, sekurang-kurangnya kalimat dalam bahasa Indonesia terdiri atas dua buah unsur pokok, yakni subjek dan predikat. Dalam kalimat yang lengkap, kedua unsur pokok itu dapat dilengkapi lagi dengan objek, komplemen atau pelengkap, dan keterangan. ${ }^{5}$

Menurut Abu Ahmadi dan Joko Tri Prasetya, strategi adalah suatu garis besar haluan dalam bertindak untuk mencapai sasaran yang telah ditentukan. ${ }^{6}$ Sedangkan menurut Arief S. Sadirman, pembelajaran adalah usaha-usaha yang terencana dalam manipulasi sumber-sumber belajar agar terjadi proses belajar dalam diri siswa kita sebut pembelajaran. ${ }^{7}$

Strategi DPLT (Dengarkan, Pikirkan, Lengkapi, dan Tuliskan) adalah sebuah srategi menulis dengan cara menyempurnakan sebuah kata yang telah ditentukan menjadi suatu kalimat sempurna yang baik dan benar. Selain digunakan sebagai strategi keterampilan menulis, strategi

${ }^{2}$ Daryanto dan Suryatri, Implementasi Pendidikan Karakter di Sekolah (Yogyakarta: Gava Media, 2013), h. 134.

3 Annis Titi Utami, "Pelaksanaan Nilai Religius dalam Pendidikan Karakter di SD Negeri 1 Kutowinangun Kebumen,” Jurnal Ilmu Pendidikan 3, no. 8 (2014): h. 22-23.

${ }^{4}$ Hasan Alwi dkk., Tata Bahasa Baku Bahasa Indonesia Edisi Ketiga (Jakarta: Pusat Bahasa, 2010), h. 317.

${ }^{5}$ Kunjana Rahardi, Kalimat Baku untuk Menyusun Karya Tulis Ilmiah (Yogyakarta: Universitas Atma Jaya, 2010), h. 4.

${ }^{6}$ Abu Ahmadi dan Joko Tri Prasetya, Strategi Belajar Mengajar (Bandung: Pustaka Setia, 1997), h. 12 .

${ }^{7}$ Arief S. Sadirman dkk., Media Pendidikan (Jakarta: Raja Grafindo Persada, 1996), h. 7. 
Muhammad Majdi, Lailatul Husna, Noor Hidayah : Strategi Menulis DPLT (Dengarkan, Pikirkan, Lengkapi, dan Tuliskan) Dalam Mengembangkan Karakter Religius

ini juga melibatkan keterampilan menyimak dalam prakteknya nanti. Hal ini dapat kita lihat pada langkah Dengarkan, dimana siswa diminta untuk mendengarkan dengan seksama kata yang disebutkan oleh gurunya. Setelah itu, pada langkah Pikirkan, siswa diminta untuk memikirkan kalimat yang sesuai dengan kata tadi. Selanjutnya, pada langkah Lengkapi, siswa diminta untuk melengkapi kalimat yang dipikirkannya tadi ke bentuk tulisan di buku tulisnya. Kemudian, pada langkah Tuliskan, siswa diminta untuk menuliskan kalimat yang sudah lengkap ke papan tulis, agar bisa dianalisis bersama teman-temannya yang lain.

Strategi DPLT ini berfungi untuk meningkatkan keterampilan menulis peserta didik, agar keterampilan menulis menggunakan tangan ini tidak hilang seiring dengan perkembangan zaman. Dimana sekarang ini lebih banyak menggunakan alat elektronik seperti Handphone dan Laptop ketika ingin menuliskan sesuatu. Selain itu, strategi DPLT ini bertujuan untuk meningkatkan minat peserta didik dalam hal tulis menulis dan bisa melatih peserta didik untuk merangkai kata menjadi kalimat, merangkai kalimat menjadi paragraf, merangkai paragraf menjadi cerita dan seterusnya. Dan apabila dikembangkan secara terus menerus diharapkan bisa menjadi sebuah karya sastra yang bermanfaat untuk orang lain.

Peneliti menggunakan strategi menulis DPLT untuk mengembangkan karakter religius adalah untuk menanamkan iman dan takwa peserta didik kepada Allah Subhanahu Wa Ta'ala, mampu bersikap baik kepada sesama (berakhlakul karimah), mampu mendorong peserta didik untuk mengimplimentasikan nilai-nilai religius di kehidupan sehari-harinya, membiasakan peserta didik untuk berdo'a sebelum dan sesudah belajar, dan membiasaakan peserta didik untuk menutup auratnya ketika proses belajar mengajar, serta mengajarkan peserta didik untuk menghormati orang yang lebih tua (gurunya) dan menyayangi orang yang seumur atau lebih muda darinya (teman-temannya). Dan yang paling utama dengan strategi menulis ini mampu mendorong minat peserta didik untuk menulis hal yang baik-baik seperti ketika belajar dan dengan menulis, peserta didik bisa mengembangkan hasil tulisannya menjadi sebuah karya sastra yang bisa bermanfaat untuk agama dan bangsanya.

\section{METODE PENELITIAN}

Penelitian menggunakan penelitian kualitatif dengan pendekatan yang bersifat induktif. Maksudnya, peneliti membiarkan permasalahan-permasalahan muncul dari data atau dibiarkan terbuka untuk interpretasi. Data dikumpulkan dengan catatan-catatan hasil observasi, wawancara yang mendalam jadi hasilnya berupa kata-kata bukan angka. ${ }^{8}$

\footnotetext{
${ }^{8}$ Nana Syaodih Sukmadinata, Metode Penelitian Pendidikan, Rosdakarya,2015), h. 60.

Al-Madrasah: Jurnal Ilmiah Pendidikan Madrasah Ibtidaiyah Vol. 6, No. 2, April-Juni 2022
} 
Muhammad Majdi, Lailatul Husna, Noor Hidayah : Strategi Menulis DPLT (Dengarkan, Pikirkan, Lengkapi, dan Tuliskan) Dalam Mengembangkan Karakter Religius

Subjek penelitian kepada 5 orang anak SD/MI yang bertempat tinggal di desa Panawakan yaitu, 1) Peserta didik pertama bernama Rabi'atul Ashfia yang berusia 12 tahun, sekarang ia bersekolah di SDIT Ihsanul Amal tepatnya di kelas 5, hobinya adalah menulis dan membaca. 2) Peserta didik kedua bernama Kayla Putri yang berusia 9 tahun, sekarang ia bersekolah di MIN 17 HSU tepatnya di kelas 4, hobinya adalah membaca. 3) Peserta didik ketiga bernama Irma Annida yang berusia 9 tahun, sekarang ia bersekolah di MIN 17 HSU tepatnya di kelas 4,hobinya adalah belajar dan bermain. 4) Peserta didik keempat bernama Riani Maulida yang berusia 9 tahun, sekarang ia bersekolah di MIN 17 HSU tepatnya dikelas 3, hobinya adalah belajar. 5) Peserta didik kelima bernama Amelia yang berusia 8 tahun, sekarang ia bersekolah di MIN 17 HSU tepatnya di kelas 2 , hobinya adalah mewarna..

Metode analisis data yang digunakan peneliti adalah data kualitatif menurut pendapat Cresswell dengan langkah-langkahnya sebagai berikut: 1). Mengkoordinasi dan menyiapkan data yang akan dianalisa, 2). Membaca, memahami, dan melihat semua data terkait Implementasi strategi tutup botol dalam pengembangan karakter rasa ingin tahu, 3). Rekapan data, 4). deskripsi lanjutan, 5). Menghubungkan antar tema yang terkait, dan 6). Memberikan interpretasi tentang tema dalam penelitian. ${ }^{9}$

\section{HASIL DAN PEMBAHASAN}

\section{Implementasi Strategi DPLT (Dengarkan, Pikirkan, Lengkapi, dan Tuliskan)}

Kegiatan belajar mengajar ini dilaksanakan pada hari Kamis tanggal 16 Desember 2021, kira-kira dari pukul 11.30 sd 12.15 di desa Panawakan. Pada kegiatan pembuka guru dengan melakukan beberapa kegiatan. Yang pertama, guru mengucapkan salam kepada peserta didik dan peserta didik pun menjawab salam dari gurunya dengan serempak. Kedua, guru menanyakan kabar kepada peserta didiknya. Ketiga, guru memimpin peserta didik untuk membaca do'a sebelum belajar dengan mengangkat kedua tangannya ke atas. Keempat, guru melakukan absensi kepada peserta didik dan mereka pun mengangkat tangan kanan mereka ketika dipanggil oleh gurunya. Kelima, guru mengadakan yel-yel ringan sebelum melakukan pembelajaran, agar peserta didik lebih bersemangat dalam belajar. Contohnya seperti tepuk semangat. Peserta didik terlihat sangat senang dengan adanya tepuk semangat ini.

Pada kegiatan inti, pembelajaran diawali dengan penyampaikan materi pembelajaran bahasa Indonesia tentang Pola Dasar Kalimat SPOK yang dijelaskan oleh guru. Di sini guru menanyakan terlebih dahulu apakah ada siswa/i yang pernah belajar materi ini sebelumnya di tempat lain. Ternyata mereka belum pernah belajar. Guru pun menjelaskan sebuah kalimat yang

\footnotetext{
${ }^{9}$ Sugiyono, Metode Penelitian Kualitatif untuk Penelitian yang Bersifat: Eksploratif Interaktif dan Konstruktif ( Bandung: Alfabeta, 2017), h. 162-163.
} 
Muhammad Majdi, Lailatul Husna, Noor Hidayah : Strategi Menulis DPLT (Dengarkan, Pikirkan, Lengkapi, dan Tuliskan) Dalam Mengembangkan Karakter Religius

berpola SPOK dan menjabarkan unsur-unsur yang terdapat di pola kalimat SPOK, seperti penjelasan tentang Subjek (S), Predikat (P), Objek (O) dan Keterangan (K). Di sini guru juga memberikan beberapa contoh kalimat dan meminta siswa menyebutkan unsur-unsur yang terdapat pada kalimat tersebut. Mereka pun sangat antusias dalam menyebutkan unsur-unsur dari kalimat yang ditanyakan gurunya. Setelah selesai menjelaskan materi, guru bertanya kepada peserta didik apakah mereka sudah paham atau belum. Karena peserta didik sudah paham, maka bisa dilanjutkan ke langkah yang kedua. Selanjutnya guru melakukan uji coba kepada peserta didik dengan melakukan latihan menulis kalimat bepola SPOK menggunakan strategi menulis DPLT.

Langkah-langkah dari strategi menulis DPLT yaitu, Pertama, Dengarkan. Di sini guru menyebutkan sebuah kata, baik itu berupa unsur subjek, predikat, objek ataupun keterangan. Guru menyebutkan sebanyak 3 kata berbeda. Peserta didik menyimak kata tersebut dengan seksama. Kemudian guru meminta peserta didik untuk mengulang kata, agar tidak terjadi kesalahan dalam menangkap kata yang disampaikan oleh guru. Mereka pun mengulang kata tersebut secara serempak.

Kedua, Pikirkan. Di sini guru meminta peserta didik untuk memikirkan kalimat yang sesuai untuk melengkapi kata yang disebutkan oleh gurunya tadi. Karena terdapat peserta didik yang masih kebingungan, maka guru pun membantu peserta didik untuk memikirkan kalimat yang tepat dengan cara memberikan dorongan (petunjuk), agar ia bisa memikirkannya sendiri, jadi tidak sepenuhnya dibantu oleh guru.

Ketiga, Lengkapi. Setelah kalimat sudah dipikirkan dengan baik, maka peserta didik pun melengkapi kata menjadi kalimat yang berpola SPOK dengan menuliskannya di lembar kertas mereka masing-masing. Di sini bimbingan guru juga sangat diperlukan, karena masih terdapat peserta didik yang belum memahami penulisan bahasa Indonesia dengan bahasa baku. Misalnya kata minum ditulis peserta didik menjadi minom. Jadi, tugas guru di sini membantu peserta didik untuk membetulkan tulisan mereka. Mereka sangat patuh kepada gurunya. Hal ini terlihat ketika mereka ditegur gurunya, mereka langsung memperbaiki tulisannya.

Keempat, Tuliskan. Setelah melengkapi kata menjadi kalimat di buku tulis mereka masing-masing, selanjutnya guru meminta siswanya maju ke depan untuk menuliskan kata yang sudah mereka lengkapi menjadi kalimat berpola SPOK di papan tulis. Guru mempersilahkan peserta didik yang ingin maju ke depan dengan mengangkat tangan terlebih dahulu. Peserta didik sangat berantusias untuk maju ke depan, sampai-sampai ada peserta didik yang sudah dapat giliran maju menulis ke depan ingin maju lagi. Peserta yang berani maju ke depan diaprisiasi dengan tepukan tangan. Kemudian guru bersama peserta didik menganalisis unsur apa saja yang terdapat pada kalimat yang ditulis oleh peserta didik di papan tulis. Peserta didik terlihat senang 
Muhammad Majdi, Lailatul Husna, Noor Hidayah : Strategi Menulis DPLT (Dengarkan, Pikirkan, Lengkapi, dan Tuliskan) Dalam Mengembangkan Karakter Religius

dan bersemangat ketika diminta menyebutkan unsur-unsur kalimat yang ditulis oleh temannya di depan.

Pada kegiatan penutup, guru menyimpulkan pembelajaran dan mempersilahkan peserta didik untuk bertanya jika masih belum jelas. Selanjutnya pembelajaran ditutup dengan membaca do'a setelah belajar secara bersama-sama. Kemudian, guru mengakhiri pembelajaran dengan mengucapkan salam dan peserta didik pun menjawab salam gurunya.

\section{Korelasi Pendidikan Karakter Religius dengan Strategi DPLT}

Berdasarkan indikator atau ciri-ciri karakter religius di paragraf sebelumnya, ternyata terdapat korelasi antara karakter religius dengan strategi menulis DPLT. Sebagaimana yang kita ketahui karakter religius adalah sikap atau perilaku patuh terhadap ajaran agamanya, dan karakter religius ini dapat terlihat ketika proses belajar mengajar yang di lakukan, yaitu 1) Peserta didik terlihat memakai pakaian yang rapi dan menutup aurat. Hal ini sesuai dengan salah satu adab ketika kita menuntut ilmu. 2) Ketika guru mengucapkan salam, peserta didik langsung merespon dengan menjawab salam dari gurunya dengan lantang dan penuh semangat. 3) Peserta didik juga khusyu' berdo'a sebelum dan sesudah pembelajaran dengan cara mengangkat kedua tangan mereka sesuai dengan adab berdo'a yang diajaran agama Islam. 4) Ketika pengabsenan kehadiran, peserta didik mengangkat tangan kanan mereka ketika nama mereka dipanggil oleh gurunya. 5) Selanjutnya ketika kegiatan menulis, peserta didik juga menggunakan tangan kanan mereka menulis kalimat di buku ataupun papan tulis. Poin 4) dan 5) ini sangat bagus untuk dibiasakan, karena menurut ajaran Islam sesuatu yang baik-baik itu harus menggunakan tangan kanan. 6) Peserta didik juga duduk dengan sopan ketika proses belajar mengajar. 7) Selain itu, peserta didik juga menampilkan sikap (akhlak) yang baik kepada guru dan teman-temannya. Hal ini bisa dilihat ketika mereka bertanya kepada gurunya ataupun meminta bantuan kepada temannya menggunakan kata-kata yang sopan dan santun.

\section{KESIMPULAN}

Pembelajaran menulis adalah salah satu keterampilan yang mampu membantu siswa memahami cara mengekspresikan bahasa dalam bentuk tulis. Pada kesempatan ini peneliti mempraktekkan strategi menulis yaitu strategi menulis DPLT (Dengarkan, Pikirkan, Lengkapi, dan Tuliskan) adalah sebuah srategi menulis dengan cara menyempurnakan sebuah kata yang telah ditentukan menjadi suatu kalimat sempurna yang baik dan benar. Materi yang digunakan adalah materi tentang pola dasar kalimat SPOK yaitu sebuah kalimat yang memiliki unsur subjek, predikat, objek, dan keterangan. Dalam mempraktekkan strategi menulis DPLT juga dapat mengembangkan pendidikan karakter religius kepada peserta didik. Karakter religius adalah sikap dan perilaku yang patuh dalam melaksanakan ajaran agama yang dianutnya. 
Muhammad Majdi, Lailatul Husna, Noor Hidayah : Strategi Menulis DPLT (Dengarkan, Pikirkan, Lengkapi, dan Tuliskan) Dalam Mengembangkan Karakter Religius

Korelasi antara strategi menulis DPLT dengan karakter religius yaitu terlihat ketika peserta didik berpakaian rapi dan menutup aurat, respon jawaban salam peserta didik, adanya do'a sebelum dan sesudah pembelajaran, mengangkat tangan kanan ketika namanya dipanggil, menulis menggunakan tangan kanan, dan selalu berperilaku yang baik terhadap sesama.

\section{DAFTAR PUSTAKA}

Abu Ahmadi dan Joko Tri Prasetya, Strategi Belajar Mengajar, Bandung: Pustaka Setia, 1997.

Annis Titi Utami, "Pelaksanaan Nilai Religius dalam Pendidikan Karakter di SD Negeri 1 Kutowinangun Kebumen," Jurnal Ilmu Pendidikan 3, no. 8 (2014): h. 22-23.

Arief S. Sadirman dkk., Media Pendidikan,Jakarta: Raja Grafindo Persada, 1996.

Daryanto dan Suryatri, Implementasi Pendidikan Karakter di Sekolah Yogyakarta: Gava Media, 2013.

Hasan Alwi dkk., Tata Bahasa Baku Bahasa Indonesia Edisi Ketiga, Jakarta: Pusat Bahasa, 2010

Kunjana Rahardi, Kalimat Baku untuk Menyusun Karya Tulis Ilmiah, Yogyakarta: Universitas Atma Jaya, 2010.

Nana Syaodih Sukmadinata, Metode Penelitian Pendidikan, Bandung: Remaja Rosdakarya,2015.

Sugiyono, Metode Penelitian Kualitatif untuk Penelitian yang Bersifat: Eksploratif Interaktif dan Konstruktif, Bandung: Alfabeta, 2017.

Zubaedi, Desain Pendidikan Karakter: Konsepsi dan Aplikasinya dalam Lembaga Pendidikan Jakarta: Kencana, 2011. 